might no longer be elusive, but the nitrogen cycle remains a treasure trove for discovery.

\section{Nicolas Gruber is at the Institute of Biogeochemistry and Pollutant Dynamics, ETH Zurich, 8092 Zurich, Switzerland. e-mail:nicolas.gruber@env.ethz.ch}

1. Redfield, A. C. in James Johnstone Memorial Volume (ed. Daniel, R. J.) 176-192 (Univ. College Liverpool, 1934).

2. Carpenter, E. J. \& Capone, D. G. in Nitrogen in the Marine Environment 2nd edn (eds Capone, D. G., Bronk, D. A., Mulholland, M. R. \& Carpenter, E. J.) 141-198 (Elsevier, 2008)

3. Gruber, N. Proc. Natl Acad. Sci. USA 113 4246-4248 (2016)

4. Deutsch, C., Sarmiento, J. L., Sigman, D. M., Gruber, N \& Dunne, J. P. Nature 445, 163-167 (2007).

5. Luo, Y.-W., Lima, I. D., Karl, D. M., Deutsch, C. A. \&
Doney, S. C. Biogeosciences 11, 691-708 (2014).

6. Knapp, A. N., Casciotti, K. L., Berelson, W. M.,

Prokopenko, M. G. \& Capone, D. G. Proc. Natl Acad. Sci. USA 113, 4398-4403 (2016)

7. Bonnet, S., Caffin, M., Berthelot, H. \& Moutin, T. Proc. Natl Acad. Sci. USA 114, E2800-E2801 (2017).

8. Wang, W.-L., Moore, J. K., Martiny, A. C. \& Primeau, F. W. Nature 566, 205-211 (2019)

9. DeVries, T. \& Primeau, F. J. Phys. Oceanogr. 41, 2381-2401 (2011).

10.Gruber, N. in Nitrogen in the Marine Environment 2nd edn (eds Capone, D. G., Bronk, D. A. Mulholland, M. R. \& Carpenter, E. J.) 1-150 (Elsevier, 2008).

11.Yang, S., Gruber, N., Long, M. C. \& Vogt, M. Glob. Biogeochem. Cycles 31, 1470-1487 (2017)

12.Kim, I.-N. et al. Science 346, 1102-1106 (2014).

13.Somes, C. J., Landolfi, A., Koeve, W. \& Oschlies, A. Geophys. Res. Lett. 43, 4500-4509 (2016).

14. Moisander, P. H. et al. Science 327, 1512-1514 (2010).

\title{
Bigger is better in virtual drug screens
}

\begin{abstract}
A system has been devised that computationally screens hundreds of millions of drug candidates - all of which can be made on demand - against biological targets. This could help to make drug discovery more efficient. SEE ARTICLE P.224
\end{abstract}

\section{DAVID E. GLORIAM}

S creening for effective drugs is tremendously expensive and inefficient. High-throughput screens can cover up to a few million compounds, but this is just a minute fraction of the total number $\left(10^{63}\right)$ of 'drug-like' molecular structures thought to exist $^{1,2}$. Moreover, typically, less than $0.5 \%$ of compounds tested in screens turn out to have activity at the chosen biological target ${ }^{3}$. There is therefore much interest in expanding the number of molecules that can be explored in the early screening stages of drug-discovery programmes, while limiting the number that need to be synthesized and assayed in the laboratory. On page 224, Lyu et al. ${ }^{4}$ achieve both these goals by computationally screening ultra-large compound libraries to prioritize compounds to be synthesized and assayed.

Physical drug-screening libraries are predominantly limited to compounds that are available in-house or off-the-shelf from commercial catalogues. By contrast, Lyu et al. docked - computationally simulated the binding of -170 million compounds that could be made on demand by a commercial supplier. More than $97 \%$ of these compounds were not available from other vendors' collections. The number of compounds in the authors' makeon-demand library has since grown, and is projected to contain 1 billion within 2 years. The authors have made this library available as a public database of $3 \mathrm{D}$ molecular structures (see go.nature.com/2sywxlt), which can be used by any researchers for virtual screening.

To evaluate how well virtual screening works with this extremely high number of chemical structures, Lyu and colleagues first investigated whether a few tens to hundreds of known ligand molecules could be distinguished within the full library of 170 million members using docking scores - which quantify how strongly compounds bind to given biological targets. The authors virtually screened the libraries against two targets: the enzyme AmpC $\beta$-lactamase and the $\mathrm{D}_{4}$ dopamine receptor. The top-scoring molecules did indeed include known ligands for these targets and their close structural analogues.

The authors went on to synthesize the topscoring compounds that had not previously been identified as ligands, as well as some analogues of these compounds. Many of these were found to be pharmacologically active in assays. Impressively, one of the compounds is the most potent AmpC inhibitor known among those that do not bind irreversibly to the enzyme (potency describes the biological response of a target to its ligand, rather than the binding affinity of the ligand for the target).

One of the $\mathrm{D}_{4}$-stimulating compounds has unprecedented affinity for $\mathrm{D}_{4}$ and selectivity for it over the related $D_{2}$ and $D_{3}$ receptor subtypes. Moreover, some of the other identified $\mathrm{D}_{4}$ ligands were functionally selective - they preferentially activated either the $G_{i}$ protein or the $\beta$-arrestin cellular signalling pathways

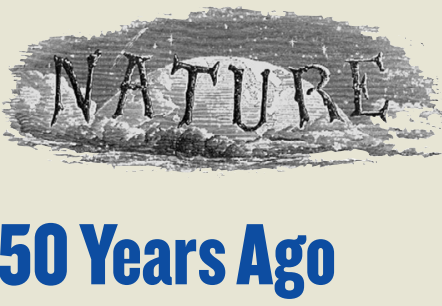

Test tube babies may not be just round the corner, but the day when all the knowledge necessary to produce them will be available may have been brought a stage nearer by the work reported by Dr R. G. Edwards and his colleagues this week ... They have fertilized human egg cells in vitro, overcoming the problem of sperm capacitation - how to obtain sperm that are in the right state for fertilization - by using a medium similar to that recently used successfully with hamster sperm ... Now that human oocytes can be fertilized in vitro, the obvious next step is to culture them to the blastocyst stage, as has already been achieved with the mouse and is likely soon with the rabbit.

From Nature 15 February 1969

100 Years Ago

While in London and examining the German guns in the Mall, I came across one with a burst shell in its breech ... The shell seems to have burst while being loaded into the gun, and, although it is well opened out, only a small portion is missing. The retained pieces are of interest, for on their inner surfaces they are covered with a large number of small patches of very fine ripple marks. These must have been produced under the intense pressure of the explosion, for it is well known that the insides of shells are turned smooth, polished, and varnished. It is, of course, difficult to say whether a study of these ripple marks will prove of scientific value, but seeing that the gun and its shell are probably exposed to the rain, and as these unique ripple marks may soon corrode away, I ... suggest that this particular gun and its shell should be protected against further injury by being removed to a geological museum.

From Nature 13 February 1919 